\title{
CONTRIBUIÇÕES DO PROGRAMA BOLSA ALFABETIZAÇÃO NA FORMAÇÃO INICIAL DO PROFESSOR: O QUE EVIDENCIAM OS RELATOS REFLEXIVOS PRODUZIDOS POR ALUNOS DE PEDAGOGIA
}

\author{
CONTRIBUCIONES DEL PROGRAMA BOLSA ALFABETIZAÇÃO EN LA \\ FORMACIÓN INICIAL DEL PROFESOR: LO QUE EVIDENCIAN LOS \\ RELATOS REFLEXIONADOS PRODUCIDOS POR LOS ALUMNOS DE \\ PEDAGOGÍA
}

\section{CONTRIBUTIONS FROM THE LITERACY SCHOLARSHIP PROGRAM IN THE INITIAL TEACHER TRAINING: EVIDENCES ON THE REFLEXIVE REPORTS PRODUCED BY PEDAGOGY STUDENTS}

\author{
Ana Silvia Moço APARICIO ${ }^{1}$ \\ Maria de Fátima Ramos de ANDRADE ${ }^{2}$
}

RESUMO: No presente artigo, apresentamos e discutimos os resultados de uma pesquisa em que buscamos compreender o processo de formação docente de alunos de Pedagogia participantes do Programa Bolsa Alfabetização, implantado pelo governo do Estado de São Paulo. Como objeto de análise foram considerados os relatos reflexivos produzidos por esses alunos, a partir de suas observações e intervenções realizadas na sala de aula de alfabetização em que atuavam junto ao professor regente. Para as análises, adotamos como referenciais teórico-metodológicos as contribuições do Interacionismo Sociodiscursivo. Os resultados apontam que a inserção dos licenciandos no cotidiano da sala de aula, ao propiciar a familiarização desse futuro professor com o processo de ensino e aprendizagem na alfabetização nas diferentes situações didáticas que emergem nesse contexto, contribuem para a reconstrução do foco de observação pelos licenciandos e para a reelaboração de suas crenças e concepções de ensino e aprendizagem.

PALAVRAS-CHAVE: Bolsa Alfabetização. Pedagogia. Formação inicial de professores.

RESUMEN: En el presente artículo, presentamos y discutimos los resultados de una investigación en la que buscamos comprender el proceso de formación docente de alumnos de Pedagogía participantes del Programa Bolsa Alfabetização, implantado por el gobierno del Estado de São Paulo. Como objetivo de análisis fueron considerados los relatos reflexionados producidos por esos alumnos, desde sus observaciones $e$ intervenciones realizadas en sala de clase de alfabetización en que actúan junto al profesor regente. Para el análisis, adoptamos como referenciales teórico metodológicos las contribuciones del Interaccionismo Sociodiscursivo. Los resultados señalan que la inserción de los licenciandos en el cotidiano de la sala de clase, al propiciar la familiarización de ese futuro profesor con el proceso de enseñanza y aprendizaje en la alfabetización en las diferentes situaciones didácticas que emergen en ese contexto,

${ }^{1}$ Universidade Municipal de São Caetano do Sul. Email: anaparicio@uol.com.br

${ }^{2}$ Universidade Municipal de São Caetano do Sul. Email: mfrda@uol.com.br 
contribuyen para la reconstrucción del foco de observación por los licenciandos y para la relaboración de sus creencias y concepciones de enseñanza y aprendizaje.

PALAVRAS CLAVE: Bolsa Alfabetização. Pedagogía. Formación inicial de professores.

ABSTRACT: This article aims to present and discuss the main results of a survey that sought to understand the teacher training process of Pedagogy students who participate in the Literacy Scholarship Program. In order to achieve this goal, it was analyzed how these students reconfigurate the teacher's acting by means of the reflexive reports they produce under the Program. The theoretical-methodological assumptions that guide the analyses belong to Socio-Discursive Interactionism. The results of the analyses indicate that the inclusion of students in the classroom everyday provide familiarization of future teachers with the process of teaching and learning, and contribute to re-building their focus of observation and for the re-development of their beliefs and conceptions of teaching and learning.

KEYWORDS: Literacy Scholarship Program. Pedagogy. Teacher training.

\section{Introdução}

Neste artigo, apresentamos e discutimos os principais resultados de uma pesquisa mais ampla em que buscamos compreender melhor o processo de formação docente de alunos de Pedagogia da Universidade Municipal de São Caetano do Sul (daqui em diante, USCS), participantes do Programa Bolsa Alfabetização implantado pelo governo do Estado de São Paulo.

O Bolsa Alfabetização é um Programa implantado desde 2007 que, a partir de uma parceria entre a Secretaria da Educação do Estado de São Paulo (SEE-SP) e a Fundação para o Desenvolvimento da Educação (FDE) e Instituições de Ensino Superior (IES), oferece oportunidades a universitários que frequentam cursos de Pedagogia ou Letras de vivenciar, junto a professores da rede pública estadual, em sistema de colaboração, a prática de uma escola real, com vistas a ampliar o significado da teoria que vêm estudando no meio acadêmico.

A tarefa dos licenciandos participantes do Programa, denominados "alunos pesquisadores" (daqui em diante, APs) é auxiliar os professores regentes de $2^{\circ}$. ano (antiga $1^{\mathrm{a}}$. série) a realizarem a alfabetização e, além disso, transformar a experiência em temário de análise e discussão na IES, onde são acompanhados e orientados por um professor orientador, com vistas a desempenharem com sucesso o trabalho de alfabetização e desenvolverem trabalhos de pesquisa sobre temas relacionados à alfabetização. A esse professor orientador, indicado pela IES, cabe realizar encontros semanais com os APs, visando orientar, discutir e refletir sobre o trabalho que estes 
realizam nas escolas. Uma das propostas da Equipe da SEE/FDE aos professores orientadores, para o acompanhamento desse trabalho, é que motivem e orientem os APs a registrarem diariamente as observações e intervenções que realizam na sala de aula em que atuam, considerando-se que a produção e análise dos registros escritos é um importante recurso de formação profissional e de desenvolvimento pessoal.

Como professoras orientadoras do Bolsa Alfabetização na USCS, chamou-nos a atenção o envolvimento demonstrado pelos APs com relação às experiências vivenciadas nas salas de aula em que atuam. Isso nos levou a refletir sobre a possibilidade de construção de um diálogo diferente, provocado pelo Bolsa Alfabetização, entre a instituição de formação docente e a instituição escolar. Diferente, sobretudo, em comparação à assimetria do diálogo entre essas mesmas instâncias, tradicionalmente instaurado pelo Estágio Supervisionado dos cursos de formação de professores.

Pesquisas sobre o assunto já demonstraram que um dos principais motivos que geram o descompasso na interação universidade-escola é que esta última, não tendo a função de formar professores, simplesmente atende às legislações oficiais, que exigem que os Estágios sejam nela realizados. Na maioria das vezes, o Projeto Pedagógico da escola não prevê espaço e tempo destinados às ações de Estágio, restando ao estagiário contar com a boa vontade do professor da sala e da direção da escola. (ALMEIDA, 1994; ARNONI, 2003; PIMENTA, 2008).

Já, ao tomar a escola como palco central da formação inicial, da formação continuada e da prática de sala de aula, o Bolsa Alfabetização tende a instaurar um espaço real em que questões da educação possam ser discutidas colaborativamente pela universidade e pela escola, permitindo a construção de novas formas de interação no processo de formação docente, inclusive com a participação de novos papéis e atores nesse processo, tais como: o professor regente, o aluno bolsista, o professor orientador.

Foram, então, essas reflexões que nos instigaram a realizar uma pesquisa tendo como foco o processo de formação dos APs e elegendo como objeto de análise os relatos reflexivos produzidos por esses alunos, a partir de suas observações, indagações, intervenções, realizadas na sala de aula de alfabetização em que atuam junto ao professor regente.

Estamos considerando "relato reflexivo" como um gênero textual de cunho autobiográfico que, de acordo com Signorini (2006), incorpora as duas funções principais que se têm atribuído a relatos de experiência pessoais escritos por professores em 
contextos de interlocução orientada para atuação no ensino - interlocução essa realizada com os seus pares e/ou com o professor formador. Nos termos da autora,

A primeira dessas funções é a de dar voz ao professor enquanto profissional. Através do "relato reflexivo", são desencadeados processos de articulação e legitimação de posições, papéis e identidades autoreferenciadas, ou seja, construídas pelo narrador/autor para si mesmo. A segunda função é a de através da interlocução mediada pela escrita, criar mecanismos e espaços de reflexão sobre teorias e práticas que constituem os modos individuais e coletivos de compreensão e de produção/reprodução desse campo de trabalho, bem como das identidades profissionais, individuais e de grupo. (SIGNORINI, 2006, p.55).

Nesse sentido, consideramos que os relatos reflexivos produzidos por APs do Programa Bolsa Alfabetização constituem um importante objeto para estudo, uma vez que, ao possibilitar a esses alunos refletir na/pela escrita sobre as práticas docentes observadas, as suas próprias ações e práticas, trazem indícios de como estão compreendendo essas práticas e constituindo-se professores. Assim, na análise que realizamos, buscamos evidenciar como os alunos de Pedagogia fazem referência, nos/pelos relatos reflexivos que produzem no âmbito do Bolsa Alfabetização, a aspectos do contexto em que atuam como AP. Com isso, foi possível desenvolver algumas reflexões sobre a formação docente dos licenciandos em Pedagogia participantes desse Programa, como também sobre a formação de professores, em geral.

No presente artigo, enfocamos, mais especificamente, na análise dos relatos reflexivos produzidos pelos APs, alguns aspectos do processo de alfabetização em sala de aula e os actantes desse processo mais tematizados pelos APs.

Para as análises, adotamos como referenciais teórico-metodológicos as contribuições do Interacionismo Sociodiscursivo (BRONCKART, 2006, 2008; MACHADO, 2009; entre outros), que assumem o papel fundador da linguagem e do funcionamento da atividade discursiva no desenvolvimento humano, enfatizando a dimensão interacional da linguagem e permitindo analisar o conteúdo e as condições de produção dos enunciados: o que é dito e os modos de dizer.

Apresentamos, primeiramente, os pressupostos e características do marco teórico do Programa Bolsa Alfabetização; na sequência, explicitamos os procedimentos de análise dos dados; e, por último, os resultados das análises e as conclusões.

\section{O marco teórico do Programa Bolsa Alfabetização}


Em linhas gerais, a proposta construtivista de alfabetização, assumida há pelo menos 25 anos pelo Estado de São Paulo, está embasada nas contribuições teóricas e metodológicas inicialmente publicadas no livro "Psicogênese da língua escrita" (FERREIRO E TEBEROSKY, 1985), amplamente divulgadas e recomendadas aos professores. Nessa obra, amparadas nas ideias de Piaget sobre a construção do conhecimento, as autoras demonstram como a criança constrói diferentes hipóteses acerca da escrita, antes de chegar a compreender a base do sistema alfabético.

Com base, então, nessa premissa, o Programa Bolsa Alfabetização alinha as concepções de língua, de alfabetização e letramento, de ensino e aprendizagem da leitura e escrita, definindo-as no marco conceitual que acompanha o seu regulamento e nos textos de orientação para a formação do AP.

Assim, no marco conceitual do Programa, a língua é compreendida como conhecimento que se organiza e se constrói nas diferentes práticas sociais de leitura, escrita, escuta e oralidade de que participam os seus falantes, cujos propósitos determinam o modo de ler/compreender e de organizar o texto oral ou escrito. Nesse sentido, alfabetizar significa muito mais do que ensinar a codificar e decodificar textos simples e, por isso, estar alfabetizado significa saber usar, de modo autônomo, os recursos da sua própria língua, nas diferentes situações de seu uso.

Essa mesma perspectiva, articulada à Investigação Didática proposta por Lerner (2002), deve embasar as estratégias de trabalho na formação de professores, que busca instigar os APs a observarem mais atentamente as situações de ensino e aprendizagem que vivenciam e a refletirem sobre como as práticas pedagógicas de alfabetização podem ser mediadas por conhecimentos sobre a didática da língua, em funcionamento em contextos reais de sala de aula.

De acordo com Lerner (2002), a investigação didática elege as práticas de sala de aula como objeto de análise, considerando as situações de classe, as diferentes formas de registros sobre essas situações e as discussões feitas a partir desses registros com os professores envolvidos, transformando tudo em ferramentas essenciais para se construir e divulgar conhecimentos próprios da/para a área.

Assumindo, então, essa abordagem para nortear o processo de formação dos APs, o Programa Bolsa Alfabetização busca envolvê-los com os problemas próprios das ações didáticas na alfabetização. Para isso, a orientação é que os APs participem do cotidiano do processo de alfabetização de crianças, observando e atuando junto aos alunos com a devida orientação do professor regente, e supervisão do professor orientador, produzindo 
registros escritos e/ou audiogravados das situações observadas/vivenciadas nesse contexto. Registros esses que devem servir para orientar o olhar investigativo do AP, bem como o foco da investigação didática a ser realizada.

\section{Seleção e procedimentos de análise dos dados da pesquisa}

Para a seleção dos relatos reflexivos que compõem o corpus da pesquisa, consideramos os que foram produzidos pelos alunos que participaram do Programa Bolsa Alfabetização na USCS desde o seu início (agosto 2008) até julho de 2011. A adoção desse critério de seleção deve-se ao fato de que, provavelmente, os APs que permanecem no Programa por mais tempo possam explicitar melhor suas observações/interpretações do trabalho que vivenciam nas classes de alfabetização.

Seguindo, então, esse critério, primeiramente, identificamos os alunos que permaneceram mais tempo no Programa: 07 APs. O passo seguinte foi separar os relatos produzidos por esses alunos entre agosto de 2008 e julho de 2011. Conseguimos reunir 75 relatos ao todo.

Os 7 APs produtores desses relatos são todos do sexo feminino, com idade entre 19 e 25 anos, provenientes da escola pública, pertencentes à classe média baixa e habitantes de regiões circunvizinhas da USCS. A maioria trabalhava como estagiárias, em escolas de educação infantil, no período inverso ao que atuavam no Bolsa Alfabetização, e no período noturno frequentavam o Curso de Pedagogia. Todas elas tinham um bom desempenho no curso e eram assíduas. De modo geral, são alunas que apresentam um domínio linguístico mediano, como poderá ser observado nos trechos de seus relatos.

Para a análise dos relatos reflexivos, utilizamos os seguintes procedimentos metodológicos:

1) Análise pré-textual: análise da situação de produção dos relatos reflexivos (o contexto físico e o contexto sociossubjetivo).

2) Análise textual

a- identificação dos conteúdos temáticos dos relatos reflexivos.

b- identificação dos principais actantes postos em cena nos/pelos textos e relatos reflexivos (professor regente, AP, alunos, pais, etc). 


\section{A situação de produção dos relatos reflexivos}

Um procedimento que adotamos até hoje na USCS, no processo de formação do AP, é a orientação para que, ao final de cada mês, o AP produza um relato reflexivo em que expressa suas observações, impressões, experiências, indagações, conflitos, autoreflexões sobre o que observa e o que vivencia na classe de alfabetização em que atua. Trata-se, portanto, de um texto de caráter mais subjetivo, em que se descreve não só os movimentos do mundo exterior como também do mundo interior, da consciência. Nesse tipo de escrita, o autor do texto deixa transparecer o seu pensamento na procura de explicações para suas observações.

Sendo assim, os relatos reflexivos são textos concebidos na esfera acadêmica, produzidos conforme os objetivos e orientações passados nos encontros de formação na USCS. O AP sabe que os seus relatos são lidos apenas pelas professoras orientadoras, e que servem de referência para as discussões nos encontros de formação e os nossos relatórios enviados à $\mathrm{FDE}$, mas sabem também que as professoras não vão revelar publicamente/nominalmente o que um determinado AP relata no seu texto. Com isso, é possível que os APs assumam em seus relatos uma forma de escrita bastante subjetiva, estabelecendo um contrato de confiança com o destinatário, o que permite inferir que haja um alto grau franqueza, pelos locutores (APs), em relação ao discurso que produzem. Os destinatários alvo dos relatos somos nós, as professoras orientadoras, podendo figurar, para o AP, a posição tradicional do professor avaliador, que valida a sua permanência no Programa, como "bolsista". Além disso, os APs também são nossos alunos no Curso de Pedagogia, o que pode configurar a produção do relato como mais uma forma de avaliação de seu desempenho como "aluno da Pedagogia" (futuro professor).

Outras posições que esses alunos podem assumir, na produção dos relatos, referem-se às funções que, comumente, são assumidas pelo AP nas salas em que atuam: pesquisador, observador, avaliador, segundo professor, professor auxiliar. Assumindo essas posições, é possível hipotetizar que esse aluno vai procurar passar uma boa imagem de sua atuação, em uma produção escrita de "pesquisador" para "orientador" ou até mesmo de "professor" para "professor". Nesse sentido, é possível que uma posição que esse aluno (o AP) tente apagar é de "estagiário", no sentido mais convencional do termo e da função. O que significa que o AP vai querer demonstrar que está desempenhando bem a sua função. 
Levantadas algumas hipóteses sobre a situação de produção dos relatos, passamos, a seguir, à apresentação das análises de texto.

\section{Principais aspectos tematizados nos relatos reflexivos}

$\mathrm{Na}$ análise textual dos relatos reflexivos, procuramos identificar quais os aspectos do processo de alfabetização de que participam são tematizados nos textos, observando quais são mais focalizados ou apagados pelos APs.

Com base nessas observações, verificamos que os relatos fazem referências às atividades de rotina das aulas realizadas pelo professor regente: atividades de leitura feita pelo professor, atividades de sondagem, ditados, produção escrita compartilhada em que o professor é o escriba, entre outras características da alfabetização.

Organizando-se, geralmente, com referência a essas atividades de rotina, os relatos se iniciam, quase sempre, referindo-se à primeira atividade da rotina do professor regente, ou então com uma ancoragem temporal, com referência ao período de observação a que se refere o relato, como nos exemplos que seguem:

\section{Exemplo 1}

Já estamos no mês de outubro e agora posso ver claramente o avanço das crianças.

\section{Exemplo 2}

Não pude notar muita diferença entre os meses anteriores e os de agora (...)

\section{Exemplo 3}

A professora inicia a aula todos os dias pela leitura, mas sem significado algum (...)

A narrativa é a sequência textual predominante nos relatos, revelando não só as experiências particulares de cada AP, mas também sua maneira de estruturar os componentes do seu relato. Contudo, para dar-lhe sentido, os autores dos relatos mobilizam seus sentimentos, impressões e conhecimentos, constituindo seus textos com a presença de diferentes sequências textuais (narração, argumentação, exposição, entre outros) e diversas vozes, tornando os relatos heterogêneos, complexos, uma verdadeira mistura de elementos, o que é característico do gênero, como se pode ver no exemplo abaixo: 


\section{Exemplo 4}

A professora foi ensinando aos poucos, todos os dias ensinava uma letrinha diferente, passava na lousa com uma letra grande e pedia para as crianças observarem os movimentos que ela fazia para desenhar aquela letra.

A professora acha que é muito cedo para ensinar a letra de mão, pois como ainda tem crianças que não são alfabéticas, vai acabar confundindo mais ainda a cabeça delas. Mas como as crianças e as próprias mães estavam insistindo ela ensinou. Agora tudo que é passado na lousa é escrito com a letra de mão, e as crianças são obrigadas a se virar.

Conclusão, uma boa parte da sala está acompanhando e fazendo direitinho, mas as crianças que não conseguem estão cada vez mais perdidas, o caderno está ficando um relaxo e as lições estão ficando incompletas, pois não conseguem acompanhar o ritmo das outras crianças.

Como se pode observar, no primeiro parágrafo, a autora do relato apresenta uma sequência narrativa de fatos, utilizando o pretérito imperfeito, distanciando-se do seu discurso, não se comprometendo, portanto, com o que é relatado. Já no segundo parágrafo, ao comentar a justificativa da professora (A professora acha que é muito cedo para ensinar a letra de mão [...] mas como as crianças e as próprias mães estavam insistindo, ela ensinou), há maior engajamento da autora do relato com aquilo que enuncia, isto é, existe uma atenção maior do locutor ao que é enunciado, criando um comprometimento com os interlocutores que estão diretamente envolvidos no discurso. No último parágrafo, assumindo uma posição mais pessoal e subjetiva, a autora do relato faz apreciações/avaliações ao comentar as consequências do agir da professora no agir dos alunos, isto é, no processo de aprendizagem desses alunos.

Pode-se verificar, também, na maioria dos relatos, no início ou no final do texto, uma avaliação global sobre o que foi observado/vivenciado ao longo de um mês pelo AP, com apreciação positiva ou negativa do agir da professora, como no exemplo abaixo:

Exemplo 5: - Trecho que aparece no final do relato

Minha professora [a professora regente], uma senhora, realmente é apaixonada pelo que faz. Intercala seus métodos, porém, ofaz de forma consciente, pois aplica atividades diferentes diante das dificuldades que os alunos apresentam, sendo, assim, acaba por recorrer ao método tradicional devido a dificuldade do aluno.

Por outro lado, compreende que são crianças e que estão passando pelo processo de adaptação, principalmente por ser uma escola de período integral. Tendo em vista isso, procura sempre manter um ambiente alegre e "infantil", decora a sala de acordo com o que está trabalhando, faz brincadeiras, e dá muito carinho e atenção, demonstrando isso para os alunos mesmo quando brava ou chateada. Leva em consideração os conhecimentos de seus alunos, seus avanços e conquistas. Concluindo, ela torna o ambiente de aprendizagem divertido, prazeroso $e$ "produtivo".

Outro aspecto típico dos relatos são as convicções ou dúvidas dos APs que podem aparecer em diferentes espaços do texto: na introdução, no desenvolvimento ou na 
conclusão, fazem intercalações, perguntas, reticências que mostram suas certezas ou incertezas sobre o ensino e a aprendizagem na alfabetização. $O$ exemplo a seguir evidencia essa característica.

\section{Exemplo 6}

A professora pediu para que eu ficasse com cinco alunas em um canto da sala para trabalhar com o alfabeto, porque elas ainda não conheciam todas as letras. Posso dizer que me desesperei e parei para pensar se isso era realmente o que eu queria.

Outro conteúdo temático recorrente nos relatos é a manifestação dos APs quanto ao ganho de experiência e à importância de sua participação no Programa, como evidencia o relato a seguir:

\section{Exemplo 7}

Participar desse projeto está sendo maravilhoso, pois estou podendo ver de perto o que acontece realmente em uma sala de aula, tanto as coisas boas como as coisas ruins. Além do prazer vivenciado a cada dia, podendo notar os progressos de cada aluno e o carinho em que demonstram ter com você, percebo que de certa forma estou fazendo a diferença para aquelas crianças.

Um fato que chama a atenção, com relação ao conteúdo temático dos relatos produzidos, é que, quando estão iniciando no programa, os APs fazem muitas referências às relações afetivas, tanto do professor regente com as crianças e com o próprio AP, quanto deste com as crianças, tema pouco frequente nos textos produzidos quando estão há mais tempo no programa. Os relatos a seguir, produzidos por APs iniciantes no Programa evidenciam essa característica:

\section{Exemplo 8}

A professora chama-se XXXX, ela é uma pessoa muito boa, é brava na hora que tem que ser, e muito amorosa quando é pra ser [...].

\section{Exemplo 9}

A relação da professora com os alunos é muito legal e de ambas as partes existe respeito e afeto o que é muito importante.

\section{Exemplo 10}

Logo que entrei no Bolsa, ao entrar em sala fiquei muito assustada ao ver a relação que a professora mantém como os alunos. Ambos não têm uma aproximação, sua relação é estritamente profissional. As vezes que ela se dirige a eles é sobre o conteúdo trabalhado em sala ou para chamar atenção. 
Além disso, no início, o agir do professor é o foco principal das reflexões; já, posteriormente, amplia-se a referência nos relatos ao agir dos alunos. Os trechos a seguir exemplificam esses aspectos e foram extraídos de relatos produzidos pelo mesmo AP em dois momentos diferentes de sua permanência no Programa: o exemplo 11 foi produzido no primeiro ano do Programa e o exemplo 12 no último ano.

\section{Exemplo 11}

A escola em que eu estou atuando como aluna pesquisadora possui uma biblioteca onde uma vez por semana a professora se dirige com os alunos para realizar momentos de leitura. Esses momentos são feitos na segunda-feira das 7:50 às 8:40, quando a professora lê textos de diversos gêneros (gibis, revistas, livros e folhetos) baseados nos temas que estão trabalhando na sala de aula. A professora sempre faz a leitura de uma forma envolvente, a professora respeita as pontuações, interage com a sala, deixa as crianças à vontade para interferir e dar opiniões, mostra as figuras explicando todos os pontos principais da história.

\section{Exemplo 12}

Neste mês observei bastante uma aluna chamada XXXXX (7 anos). Ainda em hipótese Silábica sem valor sonoro e com um comportamento nada agradável, coloquei a mesma sentada perto de mim para que eu possa ajudá-la no dia a dia, já que foram raras às vezes em que ela terminou de copiar o cabeçalho. Alguns dias se passaram e eu comecei a conversar mais com a Renata, onde, aos poucos, ela foi me desvendando seus conhecimentos e pude ajuda-la melhor. De uns dias para cá, ela vem se empenhando, melhorando e caprichando cada dia mais.

É importante ressaltar também que, embora os APs tenham o compromisso de entregar os seus textos para as professoras orientadoras, quase não se observa nos relatos referência a esses interlocutores. Certamente, isso ocorre porque não há uma preocupação dessa ordem por parte dos APs, o que aliás é uma característica do gênero relato reflexivo, de modo mais amplo.

Em síntese, os aspectos mais tematizados nos relatos reflexivos selecionados para análise giram em torno das diferentes fases de uma aula de alfabetização, podendo ser representado, de modo geral, pela rotina das aulas do professor regente, no que se refere à leitura e escrita, com descrição, comentários e avaliação pelo AP das atividades que ele considera relevantes tematizar em seu relato, seja para uma apreciação positiva e/ou negativa.

Passamos, a seguir, à identificação dos actantes postos em cena nos/pelos relatos reflexivos selecionados para análise.

\section{Os actantes postos em cena nos/pelos relatos reflexivos}


A partir da análise do plano global, procuramos identificar os actantes postos em cena nos/pelos relatos, para observar melhor se/como os APs vão (re)construindo seu foco de observação das situações de ensino e aprendizagem vivenciadas ao longo de sua participação no Programa Bolsa Alfabetização.

Estamos chamando de actantes, com base nos referenciais do interacionismo sociodiscursivo (BRONCKART, 2006, 2008; BRONCKART \& MACHADO, 2004), qualquer pessoa ou instituição implicada no agir. Por exemplo, podemos nos referir ao agir do professor regente das classes de alfabetização, ao agir do AP, ao agir do aluno, podendo, portando, ser actantes o professor regente, o AP, os alunos, entre outros implicados no agir. Assim, identificamos os actantes por meio dos marcadores de pessoa, e ainda buscamos detectar o estatuto individual ou coletivo atribuído ao agir do professor regente (PR) e do AP, isto é, quando estes são postos em situação individual ou conjunta (PR e AP), ou PR e outro(s) professor(es).

No quadro 1 abaixo é possível visualizar o total de ocorrências dos actantes nos relatos produzidos no período inicial (Período 1) de participação dos APs no Programa, compreendido entre 2008 e 2009; e os produzidos de 2010 a 2011 (Período 2), ou seja, após um ou dois anos de atuação do bolsista no programa.

Quadro 1: Actantes identificados nos relatos reflexivos do Período 1 e 2

\begin{tabular}{|l|l|l|l|}
\hline \multirow{2}{*}{ ACTANTES } & \multicolumn{2}{l|}{ Total de ocorrências por período } & \multirow{2}{*}{ Total geral } \\
\cline { 2 - 3 } & Período 1 & Período 2 & \\
\hline PROFESSOR REGENTE & 385 & 306 & 691 \\
\hline ALUNO PESQUISADOR & 92 & 164 & 256 \\
\hline ALUNO(S)/CRIANÇA(S) & 130 & 208 & 338 \\
\hline $\begin{array}{l}\text { PROFESSOR REGENTE E ALUNO } \\
\text { PESQUISADOR }\end{array}$ & 5 & 18 & 23 \\
\hline $\begin{array}{l}\text { PROFESSOR REGENTE E OUTRO(S) } \\
\text { PROFESSORE(S) }\end{array}$ & 1 & 5 & 6 \\
\hline PAIS DOS ALUNOS & 3 & 8 & 11 \\
\hline PROFESSORAS ORIENTADORAS USCS & 0 & 2 & 2 \\
\hline DIRETOR/COORDENADOR DA ESCOLA & 2 & 4 & 6 \\
\hline DIRETORIA DE ENSINO/SEE/FDE & 1 & 2 & 3 \\
\hline PROFESSORES DA PEDAGOGIA-USCS & 1 & 2 & \\
\hline
\end{tabular}

Fonte: Elaboração própria.

Como se pode verificar no Quadro 1, nos dois períodos, o professor regente é o actante mais referenciado nos relatos (385 e 306 ocorrências, respectivamente); embora no segundo período haja uma diminuição das referências ao agir do professor regente e um aumento das referências às crianças (130 e 208 ocorrências, respectivamente). Com 
isso, pode-se justificar, a nosso ver, que a maior ocorrência do actante "professor" nos relatos deve-se à concepção de ensino dos APs estar centrada no "como se ensina" em detrimento de "como se aprende". Por isso, inicialmente, o AP considera o agir dos alunos como secundário.

Contudo, nos relatos produzidos no segundo período, observa-se uma elevação da referência ao actante "aluno" (208). O que pode indicar uma (re)elaboração de concepções de ensino e aprendizagem, com a maior preocupação do AP em observar como as crianças aprendem. Vale lembrar que esse é um aspecto bastante debatido na formação dos APs na USCS, quando colocamos em discussão a análise dos registros de situações de sala de aula que vivenciam. Insistimos sempre que os APs observem e reflitam não apenas sobre como o professor ensina, mas também e, principalmente, como os alunos vão construindo os seus conhecimentos sobre a língua em seu processo de alfabetização.

Outro dado relevante nesse levantamento refere-se à ocorrência do actante AP, que aumenta de 92 (no primeiro ano) para 164 (no terceiro ano), o que pode ser justificado pelo próprio processo de construção pelo licenciando de seu espaço na sala de aula, de sua função como AP. Inicialmente, ele atua mais como observador e, aos poucos vai assumindo algumas tarefas junto aos alunos. Cabe ressaltar que essa é a orientação do próprio Programa. Obviamente, esse processo também depende da boa interação do professor regente e o AP. E, nesse sentido, pode indicar que os professores regentes, à medida que vão compreendendo melhor o papel do AP, passam a dar mais espaço para a atuação dele na sala de aula.

Por outro lado, os dados indicam que o actante AP aparece, nos dois períodos, muito mais com o estatuto de um agir individual do que coletivo, em parceria com o professor regente. Isso pode indicar que o AP atua na sala de aula separadamente do professor, com mais frequência do que em parceria.

Conforme orientações do Programa, cabe ao AP assumir, gradativamente, de comum acordo com o professor-regente e com o professor-coordenador, algumas funções para auxiliar no planejamento e execução das atividades de sala de aula, sendo que crianças com maior grau de dificuldade não podem ficar sob a responsabilidade do AP, uma vez que este pode não ter ainda embasamento teórico-metodológico e amadurecimento profissional. Contudo, os relatos reflexivos evidenciam que os APs têm atuado individualmente (sozinhos), sobretudo junto aos alunos que apresentam maiores dificuldades no processo de alfabetização. 
Quanto aos outros actantes que aparecem nos relatos, há algumas referências ao agir coletivo do professor regente com outros professores da escola, principalmente em situações de atividades de projetos culturais da escola. Já quando aparece a direção e/ou coordenação da escola, assim como Diretoria de Ensino, FDE/SEE, a referência é, geralmente, em situações de reunião na escola.

Quanto aos professores orientadores do Programa, as poucas vezes em que aparecem nos relatos, as referências são com relação ajuda/orientação desses professores para a atuação do AP nas classes de alfabetização. No caso dos professores da Pedagogia, estes são referenciados quando o AP faz uma comparação, positiva ou negativa, com o que $\operatorname{diz}(\mathrm{em}) \mathrm{o}(\mathrm{s})$ professor(es) e o que o AP vivencia na escola.

\section{Considerações Finais}

Os resultados principais da pesquisa que realizamos, apresentados neste artigo, forneceram algumas pistas que levam a uma melhor compreensão do processo de formação docente dos licenciandos inseridos em um contexto diferenciado de formação inicial propiciado pelo Programa Bolsa Alfabetização.

Nossas análises evidenciam que a inserção dos licenciandos, participantes do Programa Bolsa Alfabetização, no cotidiano da sala de aula, propicia, de fato, uma familiarização desse futuro professor com o processo de ensino e aprendizagem na alfabetização nas diferentes situações didáticas que emergem nesse contexto.

Essa experiência permite que os APs vão (re)construindo seu foco de observação das situações de ensino e aprendizagem vivenciadas ao longo de sua participação no Programa. Inicialmente, eles focalizam bastante as relações afetivas professor/aluno e, como o passar do tempo, o seu olhar se volta para o agir do professor regente em sala de aula, mas ainda um olhar "avaliador", ou seja, com apreciações positivas ou negativas das ações do professor regente em sala de aula. Vemos que ainda não há uma preocupação com o processo de ensino e aprendizagem e sim com aquilo que, ao olhar do AP, o professor faz adequadamente ou não. Com o tempo, o olhar do AP vai se ampliando, e passam a observar o agir dos alunos, ou seja, ou seja, como os alunos vão construindo seu conhecimento.

Vemos, portanto, nesse processo de formação docente, que os APs vão reelaborando suas crenças e concepções de ensino e aprendizagem e, ao que tudo indica, 
vão se tornando mais seguros e com participação mais ativa, deixando o lugar de apenas observador o observador crítico, passando a agir também, individualmente, na maioria dos casos, ou juntamente com o professor regente.

Os resultados de nossas análises permitem ainda o levantamento de questões que envolvem as ações de formação docente empreendidas não apenas pelo Programa, como também pelo contexto geral de formação de professores, principalmente, na Pedagogia. Percebemos que a reflexão sobre a ação docente tem envolvido apenas o AP. Certamente a formação do AP é o foco do Programa, mas o diálogo entre os atores envolvidos nesse contexto formativo não aparece nos relatos, como, por exemplo, entre a escola, o professor regente, o aluno pesquisador e o professor orientador da Universidade. Ao que parece, como demonstraram os relatos reflexivos analisados, tem ocorrido muito pouco diálogo entre professor regente e AP.

Como já foi apontado aqui, o Programa Bolsa Alfabetização apresenta um avanço quando possibilita ao aluno da Pedagogia vivenciar em seu processo de formação inicial as situações reais de ensino e aprendizagem, tendo a escola o papel de co-formadora desse futuro professor. Mas, certamente, o Programa ganhará mais força estabelecendo o diálogo direto da escola com a Universidade, incluindo também o professor regente nesse diálogo.

\section{Referências}

ALMEIDA, J. S. Estágio supervisionado em prática de ensino - relevância para a formação ou mera atividade curricular? ANDE, Ano 13, Nº20, p39-42, 1994.

ARNONI, M. E. B. O estágio supervisionado na vida profissional dos professores de Ciências e de Biologia: um repensar da formação do educador. In: Anais do V Simpósio em Filosofia e Ciências - Trabalho e Conhecimento: desafios e responsabilidades da Ciência (CD-ROM). Marília: Unesp Marília Publicações, 2003.

BRONCKART, J. P. O agir nos discursos: das concepções teóricas às concepções dos trabalhadores. Campinas - SP: Mercado de Letras, 2008.

BRONCKART, J. P. \& MACHADO, A. R. Procedimentos de análise de textos sobre o trabalho educacional. In: MACHADO, A. R. (Org.). O ensino como trabalho: uma abordagem discursiva. Londrina: Eduel, 2004.

FERREIRO, E. \& TEBEROSKY, Ana. A psicogênese da língua escrita. Porto Alegre: Artmed, 1985. 
GATTI, B.A. et al. Formação de professores para o ensino fundamental: instituições formadoras e seus currículos. São Paulo: Fundação Carlos Chagas: Fundação Victor Civita, 2008.

GATTI, B.A \& NUNES, M.M.R. (orgs). Formação de professores para o ensino fundamental: estudo de currículos das licenciaturas em pedagogia, língua portuguesa, matemática e ciências biológicas. São Paulo: FCC/DPE, 2009.

LERNER, Delia. Ler e escrever na escola: o real, o possível e o necessário. Porto Alegre: Artmed, 2002.

MACHADO, A. R. Trabalho prescrito, planificado e realizado na formação de professores: primeiro olhar. In: Machado, A.R. et al. Linguagem e educação: o trabalho do professor em uma nova perspectiva. Campinas: Mercado de Letras, 2009.

PIMENTA, Selma G. (org). Estágio e Docência. São Paulo. Cortez. 2008.

SIGNORINI, I. O gênero 'relato reflexivo' produzido por professores da escola pública em formação continuada. In: Inês Signorini. (Org.). Gêneros catalisadores, letramento e formação do professor. São Paulo: Parábola Editorial, 2006.

\section{Como citar este artigo:}

APARICIO, Ana Silvia Moço.; ANDRADE, Maria de Fátima Ramos de. Contribuições do programa bolsa alfabetização na formação inicial do professor: o que evidenciam os relatos reflexivos produzidos por alunos de pedagogia. Revista Ibero-Americana de Estudos em Educação, Araraquara, v.12, n.1, p. 53-69, 2017. Disponível em: <http://dx.doi.org/10.21723/riaee.v12.n1.7674>. E-ISSN: 1982-5587.

Data de submissão: $\operatorname{mar} / 2015$

Aprovação final: fev/17 